\title{
Morphology of ventricular septal defect associated with coarctation of aorta
}

\author{
ROBERT H ANDERSON`, CORA C LENOX, JAMES R ZUBERBUHLER \\ From the Division of Pediatric Cardiology, University of Pittsburgh, Children's Hospital of Pittsburgh, 125 DeSoto \\ Street, Pittsburgh, Pa 15213, USA
}

SUMmaRY It is now well established that the morphology of the ventricular septal defect associated with interrupted aortic arch is such as to compromise blood flow to the ascending aorta. Though there is some evidence that a similar mechanism may be operative in coarctation with ventricular septal defect, we are unaware of any necropsy study of this hypothesis. We therefore studied 25 hearts from the Heart Museum of Children's Hospital of Pittsburgh with coarctation and ventricular septal defect. Four had a malalignment defect with left ventricular outflow tract obstruction such as is seen in cases with interruption. Twenty of the remaining cases had a particular form of perimembranous defect with aortic overriding. The defects were partially closed by tricuspid valve tissue, the left ventricular outflow tract being further narrowed by various anatomical lesions. In addition, mitral valve malformations were present in 14 cases. The anatomy of the group as a whole suggests a possible reduction of aortic blood flow during fetal development. The clinical implications of these findings remain to be evaluated.

It is now well established that the morphology of the ventricular septal defect in hearts with interruption or atresia of the aortic arch is such that, in most cases, it diverts ventricular blood flow into the pulmonary trunk and away from the aorta. ${ }^{1-3}$ These anatomical findings are in keeping with the concept that reduced calibre of the aortic arch reflects a paucity of aortic blood flow during fetal development. Much of the physiological evidence supporting this hypothesis, however, was adduced from the small size of the aortic isthmus at birth ${ }^{4}$ and was further endorsed by the known rarity of coarctation of the aorta when there has been increased aortic flow during fetal development because of subpulmonary obstruction. ${ }^{45}$ Since a good case can be made for interruption and atresia of the aortic arch being the extreme in a spectrum of obstructive arch anomalies which start with coarctation, it might be expected that a ventricular septal defect coexisting with coarctation should also have the morphology which would jeopardise aortic blood flow during fetal development. As far as we know, this

* During the course of this investigation Professor Robert Anderson was a visiting professor at Children's Hospital of Pittsburgh, supported, in part, by the Patrick Dick Memorial Fund.

Permanent addreas: Department of Pediatrics, Cardiothoracic Institute, Brompton Hoepital, London

Accepted for publication 26 April 1983 hypothesis has yet to be tested by examination of a series of hearts at necropsy, with both coarctation and ventricular septal defect. The general study of Moulaert and his colleagues, ${ }^{3}$ however, on aortic arch malformations pointed to a likely association with coarctation. The purpose of this study was to test the hypothesis further by examination of such hearts in the Heart Museum of Children's Hospital of Pittsburgh.

\section{Subjects and methods}

There are 25 hearts in the Heart Museum of Children's Hospital of Pittsburgh which have the combination of coarctation of the aorta and a ventricular septal defect in the setting of usually arranged atrial chambers (solitus) and atrioventricular and ventriculoarterial concordance. Twenty-three of these hearts have an associated ductus and have greater or lesser degrees of aortic isthmal hypoplasia superimposed on an immediately preductal discrete coarctation. The other two hearts have a discrete coarctation lesion opposite the site of the ligamentum arteriosum. All cases were examined to determine the precise morphology of the ventricular septal defect and to see if any of its boundaries were so arranged as to obstruct ventricular blood flow into the aorta. 
Table Coarctation of aorta and ventricular septal defect in 25 cases

\begin{tabular}{lr}
\hline Ventricular septal defect & 20 \\
Perimembranous with aortic override and closure & 1 \\
Perimembranous with deviated outlet septum & 1 \\
Muscular outlet with deviated septum & 1 \\
Simple perimembranous & \\
Additional left ventricular outlet tract obstruction & 13 \\
Hypertrophic anterior lateral muscle bundle & 2 \\
Subaortic muscle bundles & 2 \\
Anomalous mitral valve tension apparatus & 1 \\
Septal bulge & 1 \\
Fibrous ridge & \\
Mitral oaloe malformations & 4 \\
Hypoplasia & 5 \\
Parachute anomaly & 4 \\
Other anomalies of papillary muscles & \\
\hline
\end{tabular}

Further examination was then made of the status of the left ventricular outflow tract and the mitral valve.

\section{Results}

The summary of the morphological findings is shown in the Table. The characteristic type of defect which produces obstruction to subaortic flow in hearts with atresia or interruption of the aortic arch is that in which the outlet septum is deviated posteriorly so that it is situated across the left ventricular outflow tract, which then opens both into a narrowed subaortic area and also to the pulmonary trunk (Fig. 1a). This malalignment type of defect was found in four of the cases with coarctation (16\%). It was perimembranous in three, abutting directly on the central fibrous body (Fig. 1b), but in the other heart it had a muscular posteroinferior rim when viewed from the right ventricle (muscular outlet defect ${ }^{6}$ ). All the other hearts had perimembranous defects without posterior deviation of the outlet septum. In one of these the defect extended only into the trabecular septum and there was no obstruction to the left ventricular outflow tract. The other 20 defects ( $80 \%$ of the total), however, had a particular morphology which appeared to compromise aortic blood flow and which was unlike that generally found in a series of hearts with perimembranous defects. ${ }^{6}$ These hearts had confluent defects which extended into all parts of the muscular septum adjacent to the central fibrous body, extending from beneath the septal leaflet of the tricuspid valve up towards the subpulmonary outflow tract. In all of these hearts the aorta overrode the central part

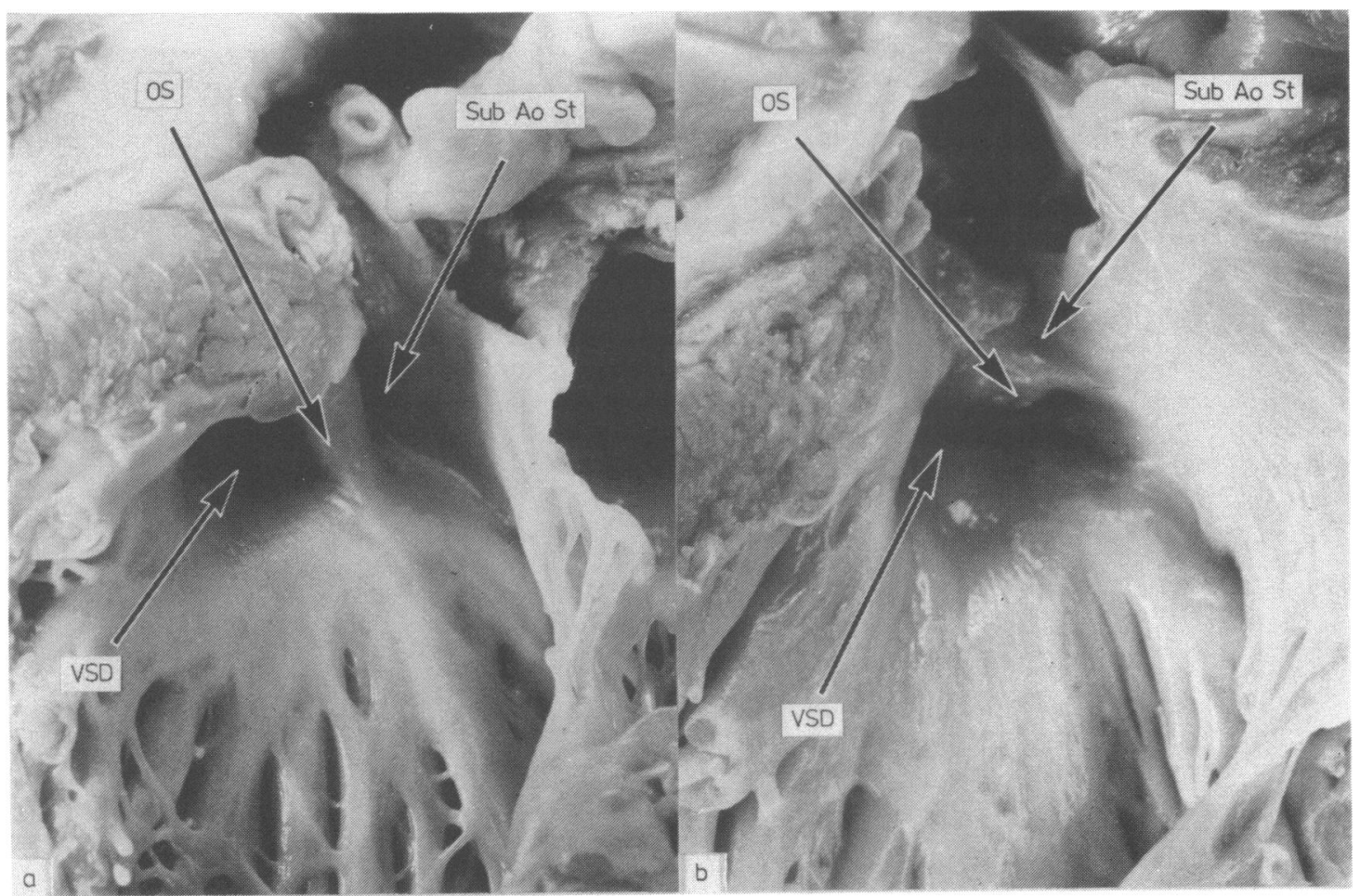

Fig. 1 The typical malalignment ventricular septal defect (VSD) in which deviation of the outlet septum (OS) obstructs the left ventricular ouflow tract (Sub Ao St). The left hand panel shows such a defect in a case with interrupted aortic arch while the right hand panel shows a heart with coarctation. 


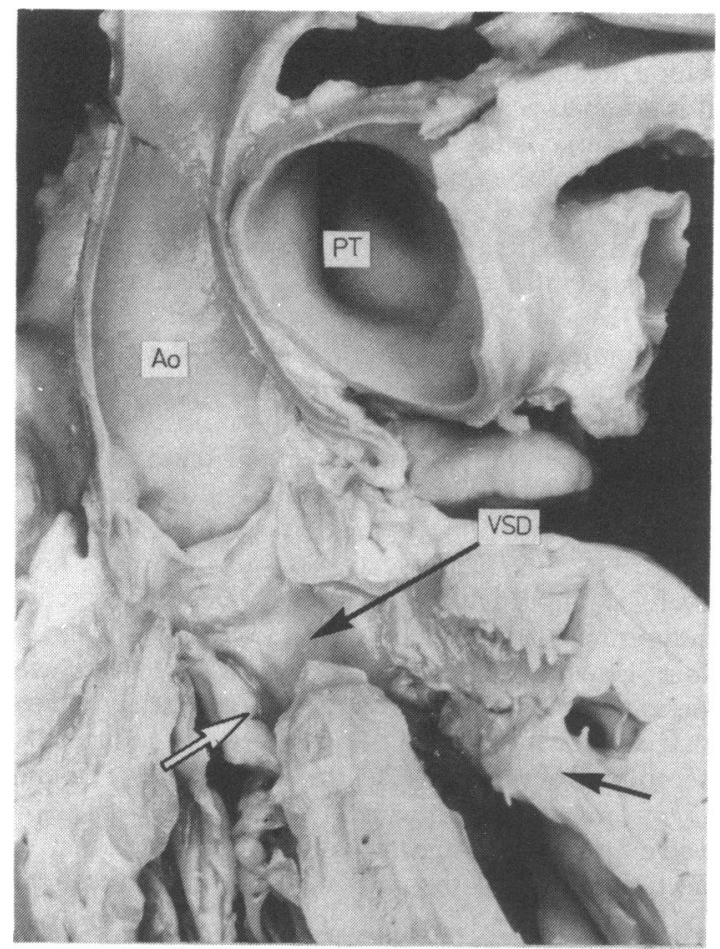

Fig. 2 A section at right angles to the long axis of the ventricular septum showing a confluent perimembranous defect with aortic overriding and discrete coarctation. The defect is partly closed by the thickened septal leaflet of the tricuspid valve (arrow) while the left ventricular oufflow tract is further narrowed by an anomalous trabecula (closed arrow). (Ao, aorta; $P T$, pulmonary trunk).

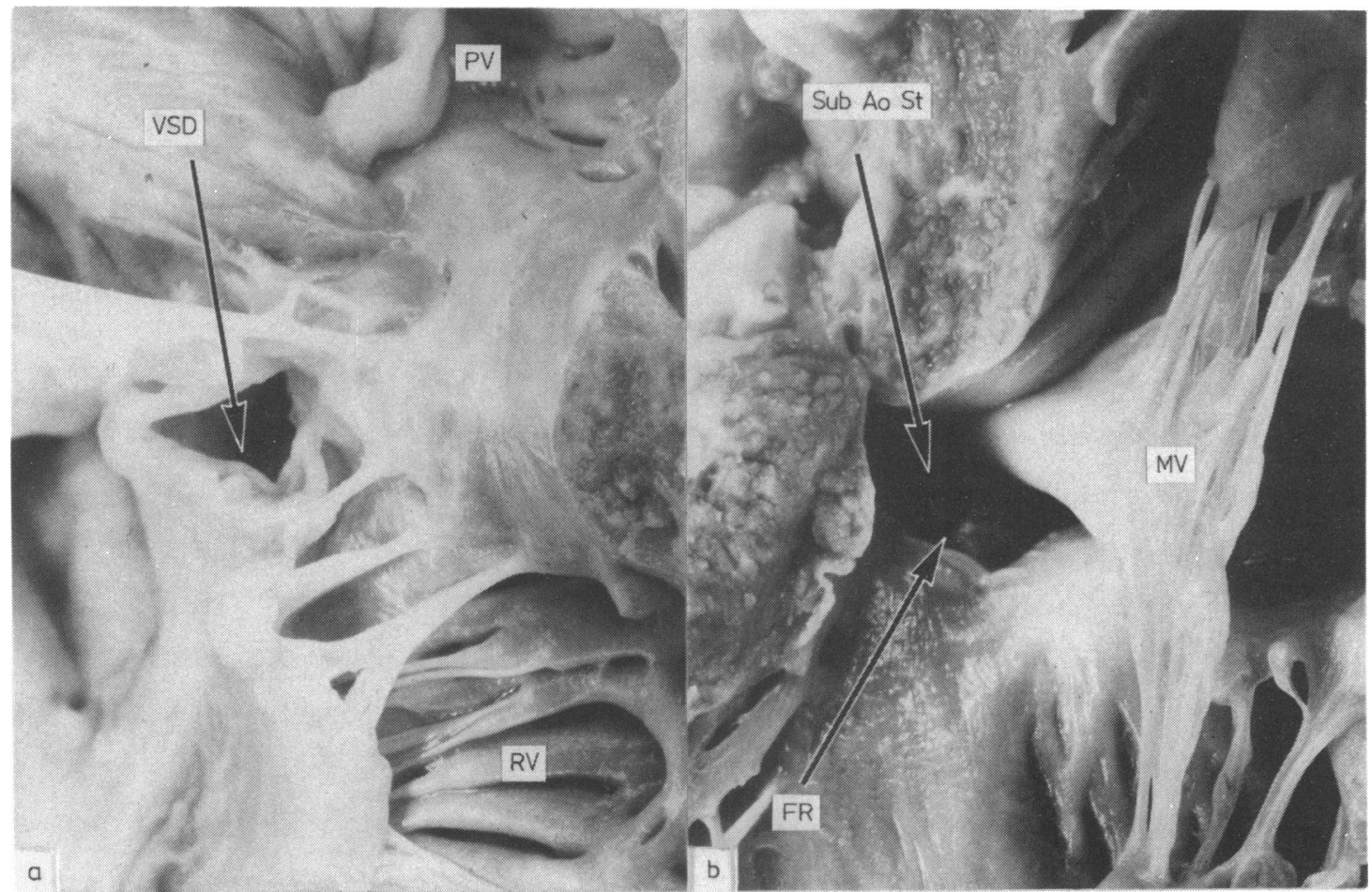

Fig. 3 The confluent perimembranous defect with aortic override found in almost fourfifths of our cases. In this case the right ventricular (RV) aspect is almost closed (lefi hand panel) while the left ventricular outlet is further narrowed (Sub Ao St) by a fibrous ridge $(F R)$ and hypertrophied anterolateral quadrant (right hand panel). (MV, mitral valve; PV, pulmonary valve). 


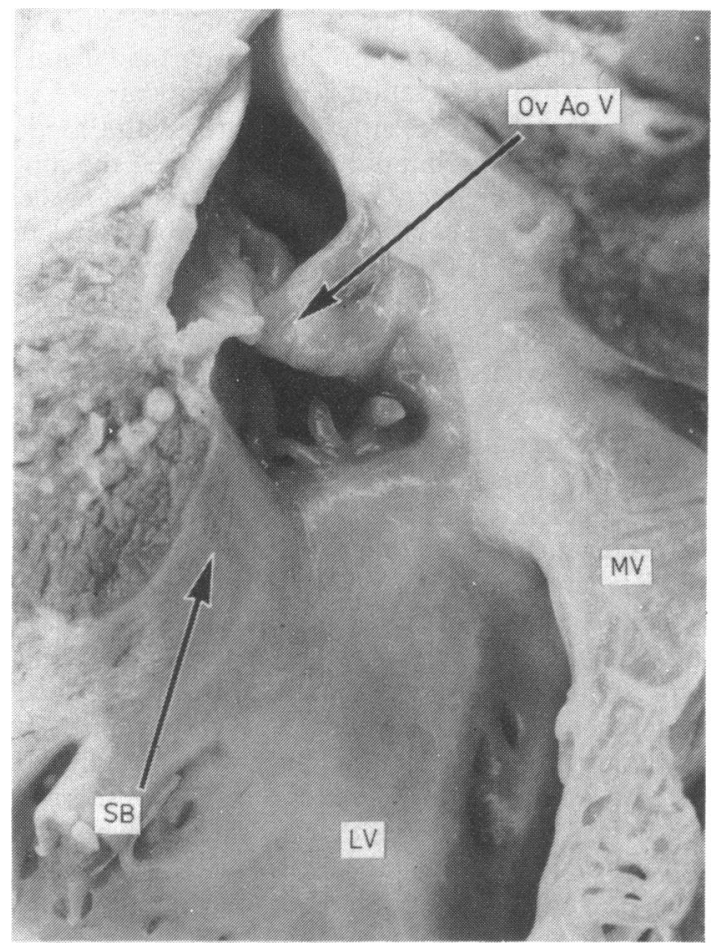

Fig. 4 The septal bulge (SB) which further narrowed the left ventricular ( $L V)$ outflow tract in one case with a perimembranous defect and overriding aortic valve (Ov AoV). (MV, mitral valve).

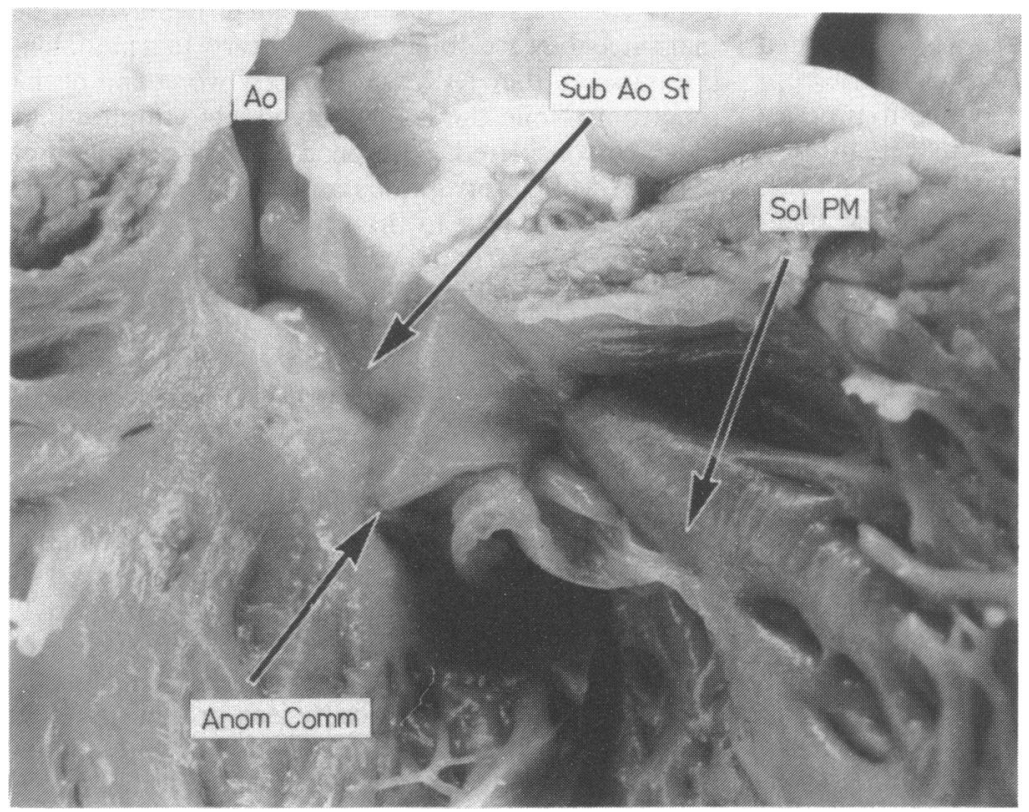

Fig. 5 A parachute mitral valve (absence of the posteromedial papillary muscle) from one of the cases with a perimembranous defect and an overriding aortic valve. Anom Comm, anomalous attachment of the posteromedial commissure; Sol. PM, solitary anterolateral papillary muscle; Ao, aorta; sub Ao St, subaortic stenosis. 
of the muscular septum, usually sitting more or less on top of the septum (Fig. 2). The right ventricular access to the defect was compromised by thickening of the septal leaflet of the tricuspid valve (Fig. 2) and/or by delamination of folds and tags of tricuspid valve tissue around the defect (Fig. 3a). The left ventricular subaortic outflow tract, already reduced in size because of the aortic overriding, was then further compromised in 19 hearts (76\%). This was produced by hypertrophy of the muscular anterolateral quadrant of the outflow tract and the anterolateral muscle bundle $^{7}$ in 13 hearts; by the presence of anomalous subaortic trabeculae (Fig. 2) in two hearts; by anomalous attachment of mitral valve tension apparatus in two hearts; by a discrete septal bulge in one heart (Fig. 4), and a fibrous ridge in the final heart (Fig. 3b).

The mitral valve itself was abnormal in 13 hearts $(52 \%)$. There was simple overall hypoplasia in four, a "parachute malformation" resulting from absence of the posteromedial papillary muscle with direct septal insertion of this commissure ${ }^{8}$ in five (Fig. 5), and other papillary muscle anomalies in the remainder.

\section{Discussion}

The haemodynamic theories which have been advanced to explain the genesis of coarctation of the aorta $^{45}$ postulate a situation that, during fetal life, would favour blood flow into the pulmonary pathways and away from the aorta. It has been well established that the ventricular anatomy in most cases of interruption or atresia of the aortic arch ${ }^{1-3}$ is such to produce this situation. Moulaert and his colleagues, ${ }^{3}$ in their study of ventricular septal defects with the specific morphology to narrow the subaortic outflow tract, noted that five of eight cases were associated with interruption of the aortic arch while two had coarctation lesions. Their study certainly suggests that similar anatomical features to those which reduce aortic flow in interruption of the aorta should be anticipated with coarctation, and our study confirms this observation. Just under one fifth of our coarctation specimens had the typical malalignment defect associated with more severe obstructive lesions of the aortic arch. ${ }^{1-3}$ The surprising finding in our study was that almost all the remaining hearts had a particular type of ventricular septal defect with the potential to reduce aortic blood flow, though not to the extent seen with a deviated outlet septum.

This particular type was a perimembranous defect which extended into all parts of the muscular ventricular septum adjacent to the central fibrous body, permitting the aortic valve to override the septum and the right ventricle. Usually aortic overriding, as in tetralogy of Fallot, is produced by anterior deviation of the outlet septum. This also narrows the subpulmonary outflow tract and produces a haemodynamic pattern in which coarctation is exceedingly rare..$^{45} \mathrm{In}$ the type of defect presently encountered the aortic valve was overriding but did not compromise the subpulmonary outflow tract. The simple feature of aortic override, however, could reduce the amount of left ventricular blood reaching the aorta. In the hearts we studied, this reduced aortic flow was additionally compromised by the tissue closing the ventricular septal defect from its right ventricular aspect and by lesions which further narrowed the already obstructed left ventricular outflow tract. Mitral valve lesions were also present in most hearts, an association previously noted by Rosenquist. ${ }^{9}$ The end result was an anatomical arrangement with the potential to produce the haemodynamic situation postulated as one cause of coarctation of the aorta. It is dangerous to speculate from morphological findings derived from hearts at necropsy to explain events occurring during fetal development. The fact that not all hearts had obstructive lesions shows that coarctation is not always related to reduced aortic flow. Furthermore, there is no way that we can be sure that the arrangement with an overriding aorta would have reduced aortic flow during fetal life. At best, therefore, our findings only suggest the aetiology of coarctation.

But, if these results are representative of coarctation and ventricular septal defect as a whole, then they are of considerable clinical relevance. It may well be that since they are obtained from hearts in a pathological museum they represent the very worst end of the spectrum. None the less, their possible implications must be considered. The poor surgical prognosis of patients with interruptions and atresia of the aortic arch relates in part to the severity of the associated lesions, particularly the ventricular septal defect morphology which militates against the aorta ever being able to support the full systemic circulation. Could this also be the case for some patients with coarctation of the aorta? The appropriate treatment for patients with coarctation in combination with ventricular septal defect remains to be established. Certainly our necropsy findings suggest that the perimembranous defect in most cases is undergoing spontaneous closure, so this argues in favour of attacking the coarctation first and leaving the ventricular septal defect. ${ }^{10}$ But will spontaneous closure be at the expense of development of left ventricular outflow tract obstruction? Or would surgical closure also produce outflow tract obstruction in those cases with a deviated outlet septum unless the outlet septum was resected at the time of operation? These answers cannot be provided by a study of necropsy material such as ours. It is therefore significant that cross-sectional echocardiographic examination of patients with this combina- 
tion has shown exactly the same types of ventricular septal defect as identified in this study. ${ }^{11}$ It will be of interest to see if these observations prove to be of therapeutic significance.

\section{References}

1 Van Praagh R, Bernhard WF, Rosenthal A, Parisi LF, Fyler DC. Interrupted aortic arch: surgical treatment. Am $\mathcal{F}$ Cardiol 1971; 27: 200-11.

2 Freedom RM, Bain HH, Esplugas E, Dische R, Rowe $\mathrm{RD}$. Ventricular septal defect in interruption of aortic arch. Am f Cardiol 1977; 39: 572-82.

3 Moulaert A, Bruins CC, Openheimer-Dekker A. Anomalies of the aortic arch and ventricular septal defect. Circulation 1976; 53: 1011-5.

4 Rudolph AM, Heymann MA, Spitznas U. Hemodynamic considerations in the development of narrowing of the aorta. Am $\mathcal{F}$ Cardiol 1972; 30: 514-25.

5 Shinebourne EA, Elseed M. Relation between fetal flow patterns, coarctation of the aorta, and pulmonary blood flow. Br Heart f 1974; 36: 492-8.

6 Soto B, Becker AE, Moulaert AJ, Lie JT, Anderson RH. Classification of ventricular septal defects. Br Heart $\mathcal{F}$ 1980; 43: 332-43.
7 Moulaert AJ, Oppenheimer-Dekker A. Anterolateral muscle bundle of the left ventricle, bulboventricular flange and subaortic stenosis. Am F Cardiol 1976; 37: 78-81.

8 Shone JD, Sellers RD, Andersen CR, Adams P Jr, Lillehei CW, Edwards JE. The developmental complex of "parachute mitral valve," supravalvular ring of left atrium, subaortic stenosis, and coarctation of aorta. $\operatorname{Am} \mathcal{F}$ Cardiol 1963; 11: 714-25.

9 Rosenquist GC. Congenital mitral valve disease associated with coarctation of the aorta. A spectrum that includes parachute deformity of the mitral valve. Circulation 1974; 49: 985-93.

10 Neches WH, Park SC, Lenox CC, Zuberbuhler JR, Siewers RD, Hardesty RL. Coarctation of the aorta with ventricular septal defect. Circulation 1977; 55: 189-94.

11 Smallhorn JF, Anderson RH, Macartney FJ. Morphological characterisation of ventricular septal defects associated with coarctation of the aorta by cross-sectional echocardiography. Br Heart f 1983; 49: 485-94.

Requests for reprints to Professor Robert $\mathrm{H}$ Anderson, Cardiothoracic Institute, Brompton Hospital, Fulham Road, London SW3 6HP. 